\title{
Improving Surface Durability of High Volume Fly Ash Concrete with Application of Alkali Solution
}

\author{
Antoni $^{1, a}$, Oswyn K. Wattimena ${ }^{1, b}$ and Djwantoro Hardjito ${ }^{2, c}$ \\ ${ }^{1}$ Postgraduate Program In Civil Engineering, Petra Christian University, Surabaya, Indonesia \\ ${ }^{2}$ Department of Civil Engineering, Petra Christian University, Surabaya, Indonesia \\ a antoni@petra.ac.id, boswyn_k@yahoo.com, 'cdjwantoro.h@petra.ac.id
}

\begin{abstract}
Keywords: Alkali Solution, Durability, High Volume Fly Ash Concrete, Sulfuric Acid Attack, and Chloride Penetration.
\end{abstract}

\begin{abstract}
This study aims to determine whether the surface durability of high volume fly ash (HVFA) concrete can be improved by applying alkali solution on its hardened surface. Concentrations of alkali solution and methods of application were studied on several $\mathrm{w} / \mathrm{cm}$ ratios and replacement percentage of fly ash in concrete mixture proportion to investigate the durability performance. Durability tests conducted were accelerated sulfuric acid attack and ion chloride penetration to investigate the improved durability of HVFA concrete. From the results, it was shown that applying alkali solution on the surface of HVFA concrete can increase its durability performance. The different $\mathrm{w} / \mathrm{cm}$ ratio and the percentage of fly ash used affect the increase in durability performance. The optimum alkali solution concentration and method of application need further research to determine their effectivity.
\end{abstract}

\section{Introduction}

Durability is one of the characteristics of construction materials that is important, especially on structural elements in aggressive environment. Often concrete in marine environment or pre-cast concrete in sewers are exposed with severe environment, especially against chloride ions penetration in seawater or sulfate attack from the soil or surrounding area. Thus it is a special concern to have higher durability property in the material.

Geopolymer concrete in several studies have been proven to have excellent durability, especially against acid attack [1,2]. Geopolymer concrete manufacturing process that uses alkali solution is still quite uncommon for most producer and consumer of concrete industry. In addition, its curing process must use higher temperature to obtain optimum strength of the geopolymer concrete, causing difficulty of mass production. On the other hand, the high volume fly ash (HVFA) concrete has been mass produced like conventional concrete and without the need of special treatment in making and curing the concrete.

In study conducted by Setyawan \& Wiratmoko[3], it was found that addition of alkali solution into fly ash concrete mix could improve the durability performance. Alkali solution is added directly into the concrete mix during the manufacturing process. However, the addition of alkali solution cause difficulty with concrete workability and lower compressive strength than the control concrete specimen.

Increasing the surface properties of concrete would increase the durability performance of the whole material, as the aggressive substance will be resisted by the higher properties of surface. In this study, alkali solution was applied to the hardened HVFA concrete surface after removal from its mould to improve the surface performance. The alkali solution did not affect the early hydration process HVFA concrete, and also the workability and strength development of concrete. By making HVFA concrete (with fly ash not less than $50 \%$ of total cementitious content), the geopolymerization process on the HVFA concrete surface with alkali solutions may improve its durability performance. 


\section{Research Methodology}

Mix Design. Mix design used in this study was a combination of $\mathrm{w} / \mathrm{cm}$ ratio and fly ash replacement ratio. Three values of $\mathrm{w} / \mathrm{cm}$ ratio which are $0.30,0.45$, and 0.60 and two values of percentage of fly ash replacement of $60 \%$ and $80 \%$ are used in this study. Therefore, there are 6 combinations of mix design as shown on Table 1 . The total of cementitious material was set at $400 \mathrm{~kg} / \mathrm{m}^{3}$. For water to cementitious ratio 0.30, naphthalene based superplasticizer was added to improve its workability. Geopolymer concrete was also made as a comparison, especially in terms of durability. The geopolymer concrete's mix design was made to meet the compressive strength of $30 \mathrm{MPa}$ and moderate workability. The alkali solution used in this geopolymer concrete was sodium hydroxide and sodium silicate; the ratio of the silicate/hydroxide was 2 by mass and the sodium hydroxide concentration was 8M [4]. Geopolymer concrete composition is also shown in Table 1.

Table 1. Mix Design Composition \& Slump Test Results

\begin{tabular}{|c|c|c|c|c|c|c|c|}
\hline Mix Design & $\begin{array}{c}\text { Water } \\
{\left[\mathrm{kg} / \mathrm{m}^{3}\right]}\end{array}$ & $\begin{array}{c}\text { Cement } \\
{\left[\mathrm{kg} / \mathrm{m}^{3}\right]}\end{array}$ & $\begin{array}{c}\text { Fly Ash } \\
{\left[\mathrm{kg} / \mathrm{m}^{3}\right]}\end{array}$ & $\begin{array}{c}\text { Fine Agg. } \\
{\left[\mathrm{kg} / \mathrm{m}^{3}\right]}\end{array}$ & $\begin{array}{c}\text { Coarse Agg. } \\
{\left[\mathrm{kg} / \mathrm{m}^{3}\right]}\end{array}$ & $\begin{array}{c}\text { Admixture } \\
{\left[\mathrm{kg} / \mathrm{m}^{3}\right]}\end{array}$ & $\begin{array}{c}\text { Slump } \\
{[\mathrm{cm}]}\end{array}$ \\
\hline F60W30 & 120 & 160 & 240 & 846 & 1034 & 6 & 12 \\
\hline F60W45 & 180 & 160 & 240 & 819 & 1001 & - & 10 \\
\hline F60W60 & 240 & 160 & 240 & 792 & 968 & - & 25 \\
\hline F80W30 & 120 & 80 & 320 & 846 & 1034 & 6 & 14 \\
\hline F80W45 & 180 & 80 & 320 & 819 & 1001 & - & 11 \\
\hline F80W60 & 240 & 80 & 320 & 792 & 968 & - & 26 \\
\hline & $\begin{array}{c}\text { Water } \\
{\left[\mathrm{kg} / \mathrm{m}^{3}\right]}\end{array}$ & $\begin{array}{c}\text { Sodium } \\
\text { Hydroxide } \\
{\left[\mathrm{kg} / \mathrm{m}^{3}\right]}\end{array}$ & $\begin{array}{c}\text { Fly Ash } \\
{\left[\mathrm{kg} / \mathrm{m}^{3}\right]}\end{array}$ & $\begin{array}{c}\text { Fine Agg. } \\
{\left[\mathrm{kg} / \mathrm{m}^{3}\right]}\end{array}$ & $\begin{array}{c}\text { Coarse Agg. } \\
{\left[\mathrm{kg} / \mathrm{m}^{3}\right]}\end{array}$ & $\begin{array}{c}\text { Sodium } \\
\text { Silicate } \\
{\left[\mathrm{kg} / \mathrm{m}^{3}\right]}\end{array}$ & \\
\hline Geopolymer & 105.2 & 57.1 & 381 & 832 & 1016 & 114.21 & - \\
\hline
\end{tabular}

Alkali Solution Application. Alkali solution used in this study was a combination of sodium hydroxide and sodium silicate; the ratio of silicate/hydroxide was 2 by mass. The sodium hydroxide $(\mathrm{NaOH})$ solution was prepared by dissolving the flakes in water. Two kinds of concentration of sodium hydroxide, which are $8 \mathrm{M}$ (A8) and 14M (A14) used to determine the effect of alkali solution in improving the durability of HVFA concrete. As inferred from studies conducted by Hardjito [4], higher concentration (in terms of molar) of sodium hydroxide solution have geopolymer with higher compressive strength, which means the polymerization process was better. The chemical composition of the sodium silicate solution was $\mathrm{Na}_{2} \mathrm{O}=17.14 \%, \mathrm{SiO}_{2}=36.71 \%$, and water $46.15 \%$ by mass.

Two methods of application were used in this study. First, alkali solution was applied directly on the specimen surface using a brush at normal condition ( $\mathrm{R}$ or room temp). Second, before applying an alkali solution, the specimen was heated using electrical oven at $80^{\circ} \mathrm{C}$ for an hour $(\mathrm{H}$ or heated $)$. For each $10 \mathrm{~cm}$ cube specimen, $20 \mathrm{ml}$ of alkali solution was used to ensure that the entire specimen surface was evenly covered.

The alkali solution was applied immediately after releasing the specimen from its moulds. For the cylinder specimen that was used in ion chloride penetration test, the application process of alkali solution conducted after the specimen was cut (when the specimen age was 7 days) in $50 \pm 2 \mathrm{~mm}$ thick. After application, the specimen was dried at ambient temperature for at least 7 days before durability testing procedure started.

Durability Testing. Durability of the HVFA concrete specimens are also tested in this study, beside the compressive strength test. Two kinds of durability test were conducted in this study which are immersion in sulfuric acid and rapid chloride penetration test. The durability tests were started when the concrete age reached 28 days. 
10\% Sulfuric Acid Attack. Cube specimen with the $10 \mathrm{~cm}$ size was used. The specimens were immersed in 10\% sulfuric acid solution for 28 days. Variables observed in this durability test were visual inspection, mass loss, and strength loss. Mass loss was observed by weighing the surface-dried specimen each week, while the strength loss was obtained from the difference in value of the compressive strength of the acid immersed specimen and the unexposed specimen.

Ion Chloride Penetration. This durability testing was conducted according to the NordTest NT-Build 492 [5], by applying electrical current on the specimen to accelerate the chloride penetration into concrete. Cast cylinders $(\phi 10 \times 20 \mathrm{~cm})$ were made for this test. The cylinders were cut into 3 parts with $50 \pm 2 \mathrm{~mm}$ thick with discarding top and bottom part approximately $2.5 \mathrm{~cm}$.

\section{Results and Discussions}

The compressive strength of the HVFA concrete reached $25 \mathrm{MPa}$ for the mix design F60W30, as seen in Fig. 1. Low strength of HVFA concrete was expected as the cement content was minimal. Mix designs with $\mathrm{w} / \mathrm{cm}$ ratio 0.60 were made in order to investigate the effect of the alkali solution application against the increase of void in concrete. With the increase of void content in the concrete, the alkali application should be able to penetrate inside the concrete. As expected, concrete with lower water cementitious ratio has higher compressive strength.

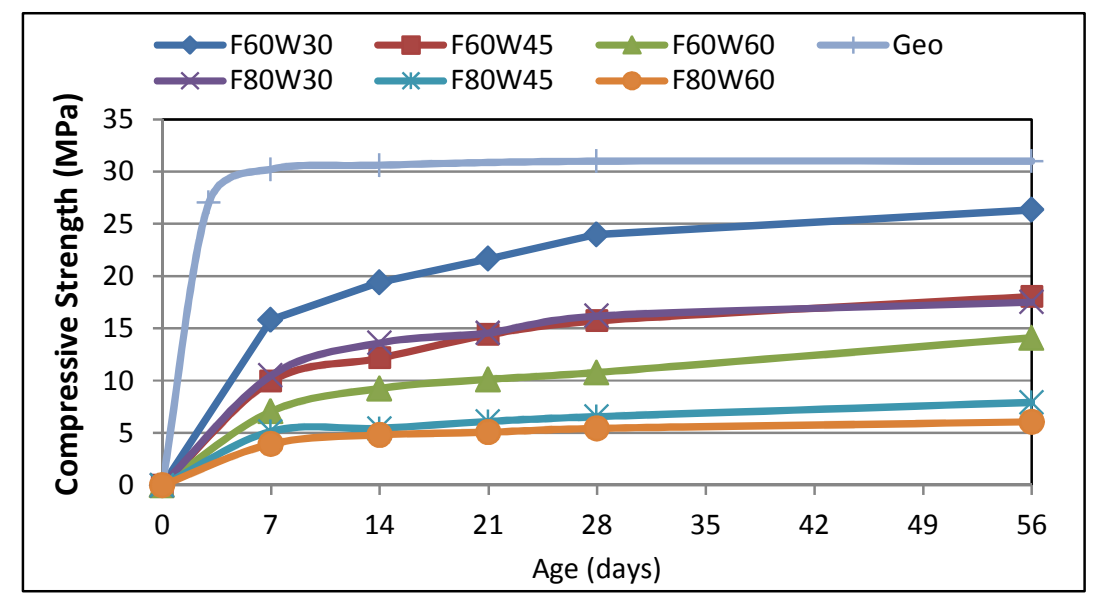

Fig. 1 Compressive Strength of the Specimen for All Mix Design

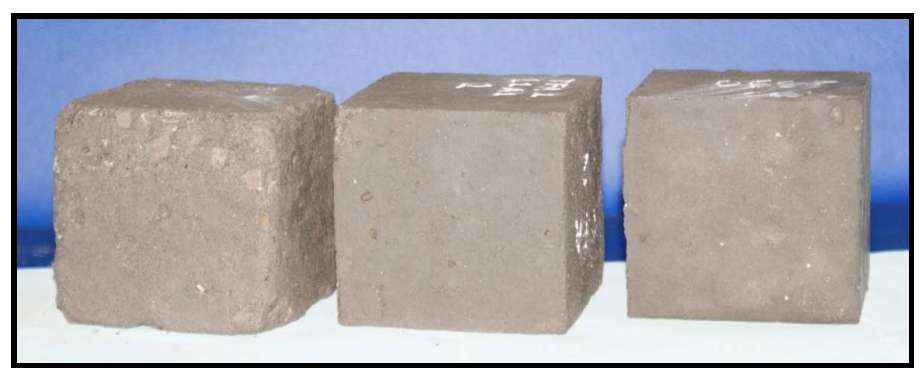

Fig. 2 Visual Inspection on Cube Specimens after Immersed in Sulfuric Acid Solution

(Left to Right: HVFAC, HVFAC with Alkali Application, Geopolymer Concrete)

Improved surface durability of HVFA concrete was observed from durability testing. Visual appearance of the cube specimen after 28 days immersion in sulfuric acid are shown in Fig. 2. The HVFA concrete applied with the alkali solution (middle specimen) had better condition which is shown with little degradation, and even almost the same as that of geopolymer concrete (right specimen) while uncoated HVFA concrete showed some degradation especially on the corner part. After sulfuric acid immersion, it was shown that changes in the surface properties by alkali solution application would result different durability performance of the HVFA concrete.

The results of mass loss measurement are shown in Fig. 3 for $60 \%$ and $80 \%$ fly ash replacement ratio. Improved durability shown by reduced mass loss as it can be seen on the treated $(\mathrm{T})$ and untreated (U) specimen for each mix design. All treated HVFA concrete have lower mass loss than 
the control specimen. Lower water to cementitious ratio tends to have higher resistance to sulfuric acid, but with the application of alkali solution on the surface, the resistance to sulfuric acid could be improved. There was also indication that higher fly ash content in concrete mixtures improved the durability of HVFA concrete at a higher rate after application of alkali solution. This could occur because more fly ash content would increase its polymerization process on the surface of HVFA concrete to a higher rate. Geopolymer concrete performed the best as it only lost less than $1 \%$ mass after 28 days immersion, followed by $80 \%$ replacement at $0.30 \mathrm{w} / \mathrm{cm}$ ratio. At higher $\mathrm{w} / \mathrm{cm}$ ratio, the 80\% HVFA concrete have lower resistance against acid solution and no difference between treated and control specimen observed, showing that lower strength concrete would not perform well.
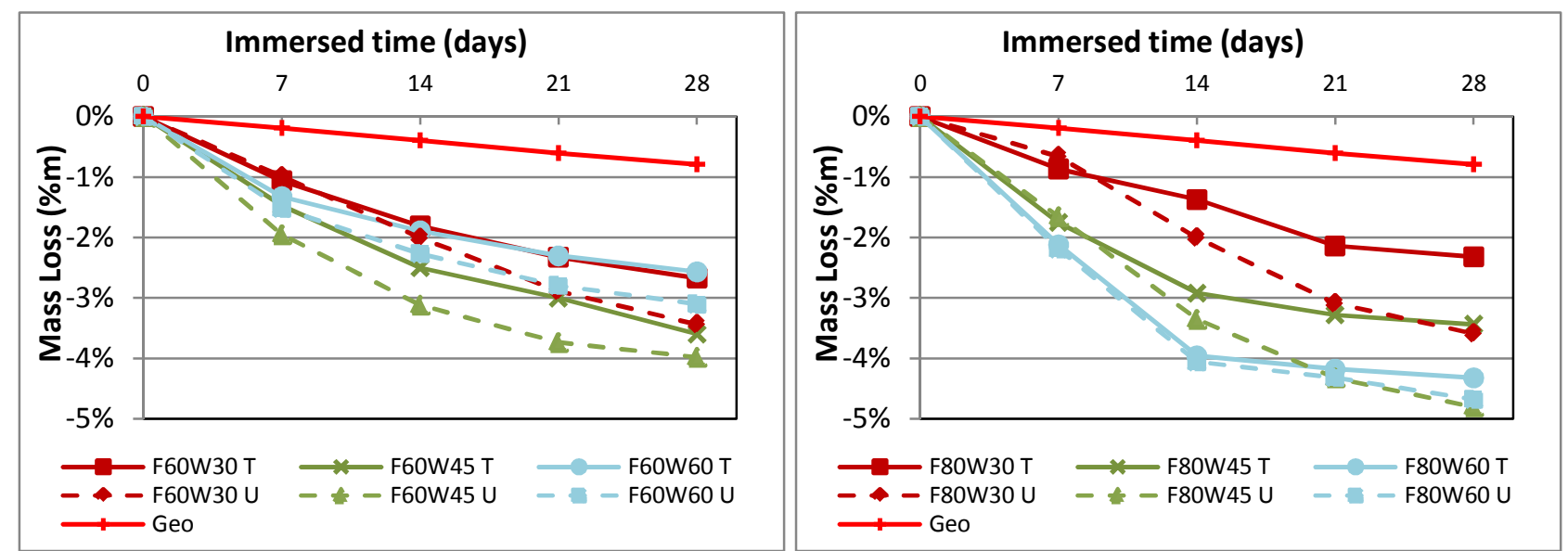

Fig. 3 Mass Loss for HVFA concrete (a) $60 \%$ fly ash and (b) $80 \%$ fly ash replacement ratio

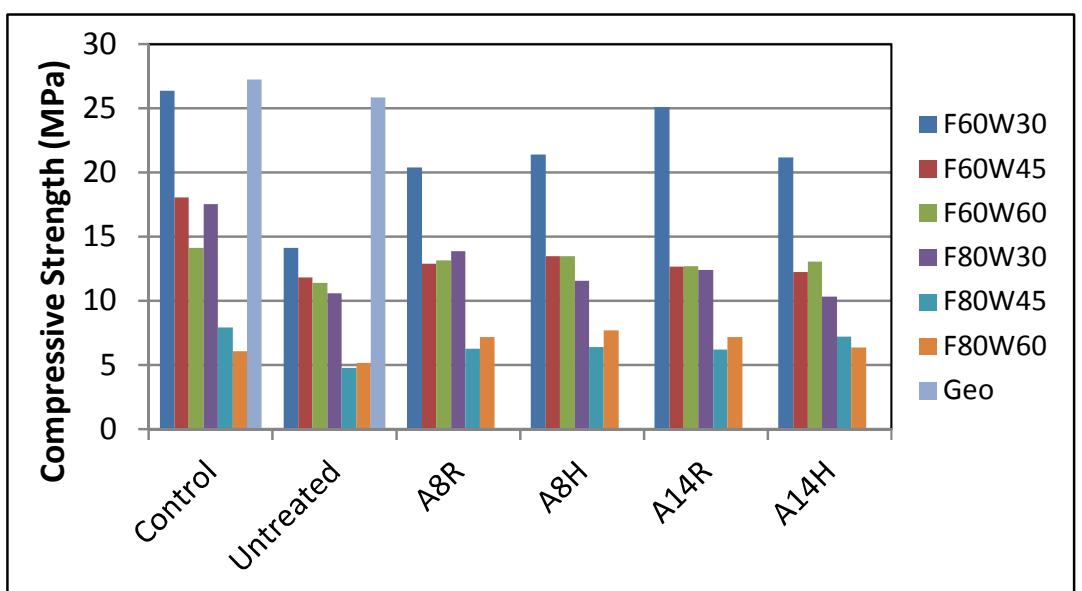

Fig. 4 Compressive Strength of Specimen After Immersed in 10\% Sulfuric Acid Solution

The compressive strengths of concrete after immersion in acid solution are shown in Fig. 4. It was clearly shown that the immersion in acid solution reduced the compressive strength of untreated specimens when compared to control (unexposed) specimen. The four methods of alkali solution application show better compressive strength when compared to the untreated specimen. However, there was no distinction on the improvement for each method. Better performance was shown on treated specimen showing that the application of $8 \mathrm{M}$ alkali solution in room condition was sufficient to improve the surface properties. The influence of alkali solution especially concentration of sodium hydroxide and method of application should be further investigated. Concrete with lower cement replacement (F60) showed higher reduction of strength, while F80 showed only small reduction, but this could be due to lower initial strength. This result shows that for concrete with higher percentage of fly ash, the total amount of cementitious material should be increased to meet designed compressive strength.

Fig. 5 shows the calculated diffusion coefficient of HVFA concrete and geopolymer specimens. The application of alkali solution on the surface of the concrete HVFA has a positive effect on increasing its resistance to chloride penetration. This is showed by the average value of the non-steady 
state diffusion (Dnssm) coefficient of treated specimen that was lower than the untreated specimen. Higher $\mathrm{w} / \mathrm{cm}$ ratio has higher diffusion value and higher fly ash content also had the same trend. Geopolymer concrete had the lowest diffusion coefficient but treated HVFA of F60W30 almost had the similar diffusion coefficient, showing the alkali solution treatment on concrete surface would have a positive result in improving the durability performance.

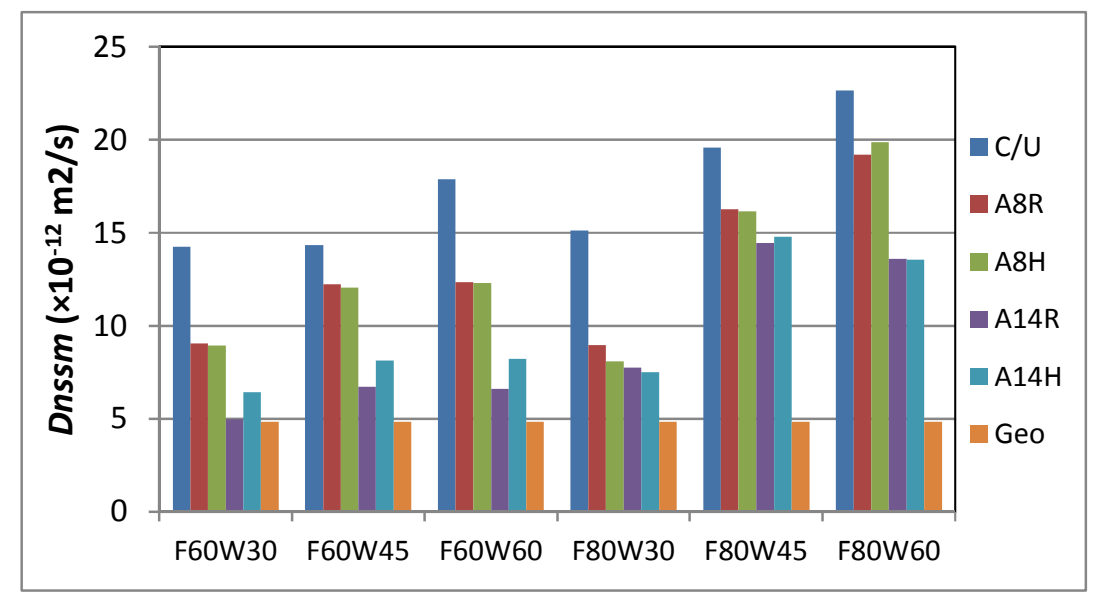

Fig. 5 Non Steady State Migration Coefficient for All Specimens

\section{Conclusion}

Improving surface durability by applying alkali solution on the surface of high volume fly ash (HVFA) concrete was studied, and gives positive results. HVFA concrete treated with alkali solution have better durability performance such as better visual condition, lower mass loss, lower strength reduction and lower diffusion coefficient when compared to untreated HVFA concrete. However, geopolymer concrete used as reference still have better performance when compared to the alkali treated specimen.

Thus the concept of increasing the durability of HVFA concrete surface by alkali activation of unreacted fly ash, such as in geopolymer concrete, is feasible, and it can be combined with the general practice of HVFA concrete that only utilize its pozzolanic reaction.

\section{References}

[1] Song, X. J., Marosszeky, M., Brungs, M., \& Munn, R. (2005). Durability of fly ash based geopolymer concrete against sulphuric acid attack. International Conference on Durability of Building Materials and Components, 10. Lyon [France].

[2] Thokchom, S., Ghosh, P., \& Ghosh, S. (2010). Performance of fly ash based geopolymer mortars in sulphate solution. Journal of Engineering Science and Technology Review, Vol.3, No.1 , pp. 36-40.

[3] Setyawan, R., \& Wiratmoko, T. (2007). Durability of fly ash concrete activated with alkali solutions. Unpublished undergraduate thesis, Petra Christian University, Surabaya, Indonesia.

[4] Hardjito, D., \& Rangan, B. V. (2005). Development and properties of low calcium fly ash based geopolymer concrete. Research Report GC1, Faculty of Engineering, Curtin University of Technology, Perth, Australia.

[5] Nordtest NT BUILD 492 (1999). Chloride Migration Coefficient from Non-Steady State Migration Experiment. Nordtest, Finland. 